\title{
Relaçao Professor-Aluno: O Poder Instituído e a Relação Transferencial
}

Francinete Alves de Oliveira Giffoni ${ }^{1}$; Hidemburgo Gonçalves Rocha ${ }^{2}$; Marta Callou Barros Coutinho ${ }^{3}$; Martha Maria Macedo Bazerra ${ }^{4}$

Resumo: A situação da relação professor-aluno em si é uma situação de aprendizagem. Esta acontece em meios a confrontos, retificações, provas, acertos e desacertos. Tais conflitos, algumas vezes, abrem possibilidades crescentes de comunicação, de forma que um possa transmitir e o outro captar a mensagem com maior fidedignidade, o que leva a compreensão entre eles. Professor e aluno, dois parceiros em papéis antagônicos e/ou complementares. Para realizarem da melhor maneira possível o empreendimento de ensino-aprendizagem, têm que usar seu aparato somato-psíquico: atenção, percepção, memória, raciocínio e todas as capacidades cognitivas e afetivas. Esta condição favorável se estabelece quando professor e aluno estão, de certa forma, esclarecidos a respeito de seus vínculos internos, o que minimizaria os efeitos potencialmente deletérios da atuação de fatores provenientes do inconsciente, tornando mais produtivo o encontro de suas intersubjetividades.

Palavras-Chave: Relação professor-aluno, Relação transferencial, Poder.

\section{Teacher-Student Relationship: The Established Power and the Transferential Relationship}

\begin{abstract}
The situation of the teacher-student relationship itself is a learning situation. This happens in the media clashes, corrections, proofs, hits and misses. Such conflicts sometimes increased communication options open, so that one can capture the other and to transmit the message with higher reliability, which leads to an understanding between them. Teacher and student, two partners in antagonistic roles and / or complementary. To realize the best possible teaching and learning enterprise, have to use your somatopsychic apparatus: attention, perception, memory, reasoning and all the cognitive and affective capacities. This favorable condition is established when teacher and student are, in a way, enlightened about their internal bonds, which would minimize the potentially harmful effects of performance factors from the unconscious, making it productive meeting your inter-subjectivity.
\end{abstract}

Keywords: Teacher-student relationship, transferential relationship, power.

\section{Introdução}

A situação da relação professor-aluno em si é uma situação de aprendizagem, através dos confrontos, retificações, provas, acertos e desacertos. Estes conflitos, algumas vezes, abrem possibilidades crescentes de comunicação, de forma que um possa transmitir e o outro captar a mensagem com maior fidedignidade, o que leva a compreensão entre eles.

\footnotetext{
${ }^{1}$ Médica. Professora da Faculdade de Medicina da Universidade Federal do Cariri - UFCA. E-mail: Fracinetealves@ gmail.com;.

${ }^{2}$ Professor da Faculdade de Medicina da Universidade Federal do Cariri - UFCA. E-mail: hidemburgo.rocha@ hotmail.com.

${ }^{3}$ Pedagoga pela Universidade Regional do Cariri URCA (1986). Especialização em Programação de Ensino de Pedagogia pela UPE. Professora da Rede Pública Estadual PE, docente da Faculdade de Ciências Humanas do Sertão Central. Mestranda PPGE UFPE.

${ }^{4}$ Pedagoga pela Universidade Regional do Cariri (1994), Especialização em Língua Portuguesa pela Universidade Estadual do Ceará (1995), Especialização em Políticas Públicas pela Universidade Regional do Cariri (2001), Mestre em Educação pela Universidade Estadual do Ceará (2013). Atualmente, cursa o Doutorado em Saúde Coletiva pela Faculdade de Medicina do ABC/SP. E-mail: dblf@ig.com.br.
} 
Quando surgem dificuldades que um ou outro não consegue resolver, pode-se inferir que há alguma patologia no vínculo. O que poderia estar acontecendo?

Normalmente, há entre professor e aluno, uma relação dialética em espiral crescente, no sentido de que um transmite informações ao outro. $O$ professor informa principalmente ao aluno a respeito do conteúdo que este deve absorver, o qual elabora e devolve o resultado do que foi compreendido de maneira transformada, não mais igual. $\mathrm{O}$ professor retoma este conteúdo, reelabora novamente, acrescentando novas informações e faz retornar ao aluno, que passa a captar, neste processo, cada vez mais profundamente, a essência da mensagem.

Quando se estuda uma relação do ponto de vista psicossocial, analisa-se a parte do sujeito que se expressa considerando-se influências contextuais na forma como se expõe e se dirige em direção ao outro.

Através das manifestações comportamentais, podemos ter uma idéia de sua estrutura psicodinâmica, da bem como, fatores que podem estar atuando sobre ela, como cultura, hábitos, costumes, nível social, entre outros. Nesse sentido, o professor que tem uma percepção ampliada destes aspectos, pode abstrair das reações do aluno manifestações e fatores de cunho pessoal que possam interferir no processo ensino-aprendizagem.

$\mathrm{Na}$ situação de avaliador, o professor poderá encontrar maiores dificuldades de se colocar como um observador "neutro", face a condição semelhante àquela do experimentador em ciências humanas, estando comprometido, de forma que os resultados afetam os dois participantes da relação, alterando sua história pessoal e posto de vista.

Através do estudo das tensões internas emergentes na relação professor-aluno, evidenciam-se aspectos da estrutura psíquica de cada um e dos fatores psicossociais a que estão submetidos. Disto pode-se tirar uma resultante do conjunto de forças que está atuando na díade: forças internas ligadas a relação transferencial, vínculos afetivos primários e forças externas, como as pressões sociais.

Para O. Manomi, In: MARIA KUPFER (1982, p.84):

(...) $\mathrm{O}$ ato de aprender sempre pressupõe uma relação com outra pessoa, a que ensina. Não há ensinos sem professor. Até mesmo o autodidatismo (visto pela psicanálise como sintoma) supõe a figura imaginada de alguém que está transmitindo, através de um livro por exemplo, aqueles saber. 
(...) Por isso, a pergunta 'o que é aprender?' envolve a relação professor e aluno, deixando completamente de lado os conteúdos que transitam do professor para o aluno e, eventualmente, do aluno para o professor .

Assim, revestidos em figuras parentais internalizadas, as figuras dos professores assumem valores relativos quando se tratem do lugar simbólico que ocupam na mente de cada aluno. O poder de credibilidade do professor, e o eco que tem sua presença na vida psíquica do aluno é algo sempre único, de um para o outro.

Nesse ponto vale lembrar o conceito de transferência de FREUD em que o aluno vê no mestre suas figuras de mundo interno, e o processo de contra transferência quando o professor complemente essa relação "neurótica".

Tomando por exemplo, o caso de Rodrigo, 12 anos, que leva muito a sério as tarefas escolares, procure atender as solicitações dos professores, principalmente do Prof. Manuel que é rigoroso e exigente, como seu tio Alfredo. Rodrigo, como os colegas temem qualquer repreensão deste professor mas no caso, com um agravante. Qualquer admoestação do professor de toma para si, chega a sonhar com castigos e espera estas agradando ao professor em Particular com se este também o aprecias-se a mais do que ao outro alunos. Se por acaso o Prof. Manuel entrar num processo de complementar essa relação simbólica, até certo ponto, neurótica, e, começa a dar demasiada importância aos receios de Rodrigo, e também repreendê-los mais que aos outros, ou mesmo pensar nele, quando volta para casa no trânsito, estará concretizando o processo de contra-transferência.

De acordo como a criança tiver elaborando seu complexo de Édipo é que atribuirá a importância a professora, e à professora, e disso depende o poder de influência destes sobre o aluno.

Segundo M. KUPFER (1992) essa já é uma idéia bastante conhecida e atribuída a FREUD quando diz:

No decorrer do período de latência, são os professores e geralmente as pessoas que têm a tarefa de educar que tomarão para a criança o lugar dos pais do pai em particular e que herdarão os sentimentos que a criança dirigia a essa último na ocasião do complexo de Édipo. Os educadores, investidos da relação afetiva primitivamente dirigida ao Pai, se beneficiarão de influência que esse último exercia sobre a criança.

Assim, na perspectiva psicanalítica, entre o professor e o aluno o fator mais importante que a transmissão dos conteúdos é o campo de relação que se estabelece entre 
eles. Esse campo interacional pode ser considerado o que em psicanálise chama-se transferência.

Esse termo foi usado por FREUD, pela primeira vez em 1900, no livro $A$ interpretação dos sonhos. É uma manifestação do inconsciente que pode ocorrer do paciente com o analista, do professor com aluno, e assim, esse fenômeno é como se o acontecimento da vida afetiva precoce, ganhassem vida novamente. $\mathrm{O}$ que para FREUD acontecia na relação transferencial do médico com o paciente, pode ser aplicado ao que ocorre numa relação pedagógica entre alguém que ensina ao outro que aprende, como a repetição atualizada de como o pai ensinava ao filho. Assim, o que se transfere é o conteúdo afetivo das experiências vividas primitivamente com os pais.

O conhecimento desse fenômeno tem tanta importância para o analista quanto para o professor, em que transferir é atribuir a determinada pessoa um sentido especial e também um poder. Dessa forma, aquilo que o professor fala, além de ser um conteúdo científico, por exemplo, com revestido de um sentido especial, que pode inclusive fazer o aluno gostar ou não da matéria. E também pode explicar peque para um aluno a repreensão do mesmo professor é de maneira tão forte, enquanto outro a ignore.

Então uma que na sublimação do sexualidade, as pulsões se convertem, o desejo de saber, se encontre um o poder atribuído ao mestre, na transferência.

O acontecimento vai transitar através destes filtros afetivos, que devem ser considerados para se dêem de maneira o mais saudável possível os processos de ensino e aprendizagem.

Entendendo do que se trata a relação transferencial, o professor modulará suas intervenções no processo de desenvolvimento intelectivo do aluno, colocando-se como um facilitador.

Segundo M. KUPFER, o professor é também um sujeito marcado por seu próprio desejo inconsciente. Aliás é exatamente esse desejo eu impulsiona para a função de mestre. Por isso o jogo todo é muito complicado. Só o desejo do professor justifica que ele esteja ali. Mais, estando ali, ele precisa renunciar a esse desejo.

A relação entre o professor e seu aluno acontece no momento presente e tem nestes aspectos presentes diversas nuanças a serem observadas. Além do que já foi visto, queremos trazer ainda um pouco da história antiga, de pai para filho, de avô para neto, os álbuns de família e os resquícios de uma relação que transcende o tempo, a relação com as 
figuras parentais, as primeiras impressões de um mundo grande e misterioso, cheio de normas e com desejo de colo...

\section{Professor e Aluno, Sujeito e Objeto: A Patologia do Vínculo}

O conhecimento, no contexto educacional transita no fluxo relacional da díade professor-aluno; enquanto um é sujeito cognoscente, o outro é objeto cognoscível. O sujeito cognoscente tem a capacidade de conhecer e o objeto a de ser conhecido. O conhecimento pressupõe a existência destes dois elementos numa interação de influência mútua.

Numa interação interpessoal o sujeito alterna sucessivamente sua posição, sendo ora cognoscente, ora cognoscível, quando está conhecendo ou sendo conhecido, respectivamente, podendo tal processo acontecer simultaneamente numa inter-relação de subjetividades.

O professor enquanto sujeito, toma uma atitude ativa indo em direção ao objeto (aluno), em busca de conhecê-lo, de captar suas características. Neste momento, sua percepção é modificada em função da alteração produzida nesse conhecimento, começando a se formar dentro dele uma "imagem" interna - do objeto (aluno). Esta imagem contém apenas algumas das propriedades do objeto.

Já com respeito ao aluno, enquanto sujeito do conhecimento toma uma atitude no sentido de conhecer o professor (objeto), captando também algumas de suas características, com as quais forma a "imagem" interna do professor. Como se saberia se as imagens formadas corresponderiam aos objetos? Qual o grau de fidedignidade desses registros?

Sempre haverá um pouco de dúvida na consciência cognoscente e uma margem para reformulação da "imagem" do objeto, em ambas as situações. No campo da subjetividade, é pouco provável o estabelecimento de uma certeza como critério de verdade, vez que diversos fatores estarão influenciando a exemplo, o processo de formação desta “imagem”.

FREUD (1856-1939) em seus estudos coloca que todo ser humano, no seu início de vida, na relação mãe-filho, começa a formar os primeiros objetos de conhecimento. Tais objetos são cognitivo-afetivos. As relações iniciais do sujeito com estes objetos vão influenciar as relações objetais posteriormente estabelecidas no decorrer da vida. Como já foi citado anteriormente, FREUD explicou o fenômeno da transferência, quando o conteúdo afetivo encontrado entre o indivíduo e suas imagens internas, reflete-se em suas relações externas, geralmente com figuras de autoridade, como acontece entre professor e aluno. 
Também foi evidenciado ao fenômeno da contra-transferência, em que o professor reage à forma como é percebido pelo aluno.

PICHON RIVIÈRE (1986), refere-se ao relação objetal como uma estrutura composta de sujeito e objeto interligados num dinamismo contínuo, propulsionando por fatores instintivos, quanto ao conceito de vínculo refere-se da seguinte maneira:

Podemos definir o vínculo como uma relação particular com o objeto. Esta relação particular tem como conseqüência uma conduta mais ou menos fixa com este objeto, formando um pattern, uma pauta de conduta que tende a se repetir automaticamente, tanto na relação interna quanto na relação externa como objeto. (PICHON RIVIERE; 1986, p. 37).

Enquanto na relação objetal temos apenas a estrutura interna do vínculo originada pela figuras parentais internalizadas, o vínculo inclui a conduta, o comportamento expresso nas relações externas, a face externa do vínculo. O aparelho psíquico comporta-se como uma totalidade, tendo uma face interna e outra externa. “(...)Os vínculos internos e externos se integram em um processo que configura uma permanente espiral dialética. Produz-se uma passagem constante daquilo que esta dentro, para fora e do que esta fora, para dentro." (PICHON RIVIERE; 1986, p. 15).

Numa relação entre duas pessoas, por exemplo: professor e aluno, os vínculos internos conectam-se com os externos, retroalimentando-se, de forma que as condutas (manifestações comportamentais) de cada um revelam aspectos da personalidade, portanto de seus mundos internos. São fases de uma mesma moeda, de forma que PICHON RIVIERE (1986, p. 16), considera (...) impossível separar o aspecto exterior da conduta do aspecto interior da vivência, já que ambos formam um todo em situação em um dado momento, no aqui-agora de qualquer situação".

O vínculo interno, reflete o grau de desenvolvimento da relação objetal, estabelecida inicialmente entre mãe e filho e das demais relações familiares através da internalização e incorporação das figuras parentais. Quando isto acontece de forma satisfatória, as condutas do indivíduo no ambiente tendem a demonstrar este grau de maturidade, tanto no equilíbrio deste sujeito com relação a si mesmo, quanto nas suas relações pessoais.

No caso, quando professor e aluno têm um nível de maturidade emocional que permita uma independência afetiva, forma-se um vínculo flexível e saudável. 
Por exemplo: o sujeito $\mathbf{A}$ tem um vínculo saudável com sua mãe, no que diz respeito à maturidade afetiva. Neste caso, a mãe terá com este sujeito uma vinculação interna através da representação mental que ele faz ou constrói a partir do seu relacionamento primitivo com ela. Por outro lado, o vínculo se refere às relações quotidianas entre o sujeito $\mathbf{A}$ e sua mãe.

Pode-se dizer que o fator mais interessante do ponto de vista psicossocial é o vinculo externo, enquanto que, do ponto de vista da Psiquiatria e da Psicanálise, aquilo que mais interessa é o vínculo interno. Na perspectiva da abordagem psicanalítica, portanto, deve ser compreendida a forma particular que o sujeito tem de se relacionar com a imagem do objeto representada dentro dele.

Quando o vínculo interno é relativamente estável, isto se reflete nas características comportamentais do sujeito manifestadas externamente, seu modo de ser. Assim, através da expressão desse sujeito no ambiente revela-se a forma como ele está se relacionando com seu objeto interno.

O aluno manifesta comportamentos no ambiente, tanto no aspecto da aprendizagem em si, quanto no aspecto das relações humanas. O professor, da mesma forma, nas atitudes diretamente ligadas ao ensino e também nas relações humanas revela de que maneira estão representadas, dentro do psiquismo, as figuras parentais (pais, avós, tios), e o contexto escolar (as relações de autoridade, a questão do conteúdo, o processo avaliativo, etc.). O comportamento pode ser uma pista de acesso a estas representações.

Por esse ângulo da psicologia podemos evidenciar quando se expressa numa relação inter-pessoal a interferência de conteúdos inconscientes. Em geral ocorrem reações emocionais inadequadas ou desproporcionais a uma situação que certamente funcionou como fator desencadeante, tomemos por exemplo um incidente acontecido numa sala de aula de quinta série do primeiro grau numa escola pública de Fortaleza, em que durante a aplicação de uma prova de matemática a professora comunica aos alunos que vai verificar de um por um se alguém trouxe "cola".

Em seguida, a professora começa a revistar as carteiras, examinar os objetos escolares, e até o corpo dos alunos para verificar se não tinham as informações anotadas. Mariana, uma aluna de 12 anos, demonstra inquietação, olhando para os lados, roendo as unhas, com respiração ofegante. Parece sentir-se extremamente angustiada. Tem uma crise de choro, soluçando. Ela não tinha trazido "cola" e até estudou bastante para a prova. O que pode Ter acontecido no intimo de Mariana que motivasse a expressão de seu sentimento dessa forma? 
A nosso ver o estímulo desencadeante foi a atitude da professora de fiscalizar os alunos. Esta situação deve ter disparado no psiquismo da aluna, um circuito neuronal onde estava registrada a lembrança do dia em que seu pai a acusou de ter retirado dinheiro da carteira dele e, mesmo sem comprovação do fato, castigou-a severamente, impedindo-a de chorar, com repreensões do tipo: "cale a boca agora!".

Mariana convive com o pai e se submete repetidamente a situações como essa, de forma que estabeleceu com ele internamente um vínculo persecutório, que se estende às relações externas com autoridades.

Na sala de aula, ao ser confrontada com a atitude autoritária da professora reage de forma confusa, deixando fluir conteúdos de seu mundo interno, como o sentimento de ser acusada e a "certeza" de que seria punida injustamente. A situação ocorrida na sala de aula, de alguma forma teria semelhança com aquelas vivenciadas na relação com o pai, despertando a reação comportamental relativa ao vínculo que Mariana estabelecia com ele, e não ao vínculo externo que vem estabelecendo no momento presente com a professora.

Este exemplo ilustra de que forma, na relação professor-aluno, um e outro assumem o papel de sujeito e objeto alternadamente. Os vínculos internos, num e noutro, vão estar emitindo ordens para o organismo, determinando como devem se comportar e que posicionamento devem assumir nesta ou naquela situação, as estratégias de ação e a maneira de funcionar no ambiente. Condicionam ainda, o grau e tipo de afetividade que cada um pode estabelecer, enquanto sujeitos com os objetos com os quais se relacionam, incluindo, além de pessoas, animais, conteúdos, teorias, lazer e trabalho.

$\mathrm{Na}$ investigação dos diversos papéis que toda pessoa assume simultânea e sucessivamente durante sua existência, a análise do grau de coerência entre eles, assim como a seqüência com que são assumidos, são fundamentais para que se possa determinar o grau de maturidade da personalidade do sujeito em questão. (PICHON RIVIERE, 1986, p. 17).

Esses dois parceiros, professor e aluno, em papéis antagônicos ou complementares, para realizarem da melhor maneira possível o empreendimento de ensino-aprendizagem têm que usar seu aparato somato-psíquico: atenção, percepção, memória, raciocínio e todas as capacidades cognitivas e afetivas. Esta condição favorável se estabelece quando professor e aluno estão, de certa forma, esclarecidos a respeito de seus vínculos internos, o que minimizaria os efeitos potencialmente deletérios da atuação de fatores provenientes do 
inconsciente, tornando mais produtivo o encontro de suas inter-subjetividades. Transcendendo as questões interpessoais, podem chegar ao que LOBROT (In: MOACIR GADOTTI 1993) chamou de Pedagogia Institucional, aquela prática pedagógica em que a escola teria como meta tornar as pessoas menos dependentes, e a partir da diáde professor-aluno, enquanto micro-sistema, na sala de aula, chegaria um processo de transformação da instituição escolar, seguindo-se de um processo de transformação da própria sociedade.

\section{O Espaço Virtual do Professor Particular}

No espaço virtual entre os conteúdos não aprendidos e as próximas provas surge a figura do professor particular. Atesta a incompetência do sujeito de aprender sozinho, ou atesta que os métodos não estão sendo satisfatórios? Será a demanda do aluno de ficar com alguém só prá ele? Ou gostaria mesmo; e de estudar com a mãe? Esta castigando os pais ou realmente é um pedido de auxílio, mas de outra natureza?

No instante em que a mãe delega ao professora particular a função de auxiliar do filho, ela entra no papel de fada e conscientemente deverá facilitar a aprendizagem do aluno. $\mathrm{O}$ aluno chega fragilizado, geralmente em baixa auto-estima e humilhado. Entra numa relação complementar onde buscará receber: além dos conteúdos, compreensão e espera também o controle que, vindo de fora o auxilia a produzir mais.

O professor particular por sua vez tende a querer mostrar através da nota (é o parâmetro utilizado para mostrar sua competência) que fez um bom trabalho. O aluno em geral se envolve emocionalmente com todas essas questões diante do professor particular, sendo mais um motivo de tensão para ele Ter que mostrar para os pais que o professor é "bom" na matéria (isso quando ele quer continuar com o professor). Quando ele não gosta do professor poderá inconscientemente sair-se mal nas provas para mostrar para os pais a incompetência do professor de quem tenta se livrar.

Muitas vezes o jovem aluno torna-se impotente diante dessa articulação de papéis. Ele está no meio de ansiedades e é jogado de um lado para o outro. Se a escola é de nível A, por exemplo, considerando que a escola com alta freqüência de aprovação no vestibular, e o aluno 
está no $1^{\circ}, 2^{\circ}$ ou $3 .^{\circ}$ ano ele já é mais observado e quando não vai bem, pode ter o professor particular ou pedir ajuda aos colegas. Suas notas colocam em risco a imagem do colégio. Em alguns casos os pais temem que o filho seja convidado a deixar a escola.

\section{Referências}

GADOTTI, Moacir. A organização do trabalho na escola: alguns pressupostos. São Paulo: Ática, 1993

KUPFER, M.C. Freud e a Educação: o mestre do impossível. São Paulo: Editora Scipione, 1992.

PICHON-RIVIÈRE, E. O processo grupal. São Paulo: Martins Fontes, 1986.

\section{Como citar este artigo (Formato ABNT):}

GIFFONI, F.A.O.; ROCHA, H.G. COUTINHO, M.C.B.; BEZERRA, M.M.M. Relação Professor-Aluno: o poder instituído e a relação transferencial. Id on Line Revista de Psicologia, Fevereiro de 2015, vol.9, n.25, p. 243-252. ISSN 1981-1189.

Recebido: 12/01/2015

Aceito:22/01/2015 